\title{
EVALUATING DRIVER BEHAVIOR IN YELLOW INTERVAL AT SIGNALIZED INTERSECTIONS
}

\author{
NASREEN AHMED HUSSEIN ${ }^{1}$ \\ Dept. of Civil Engineering, College of Engineering, University of Duhok, Kurdistan Region-Iraq
}

(Accepted for Publication: December 8, 2020)

\begin{abstract}
Signalized intersection is one of the most popular type of control at intersections in urban areas. Study of the elements of this type of control is vital to reduce accident rate, improve performance, and decrease delay. Yellow period is one of the parameters which has influence in performance of these type of intersections specially accident rate. At the indication of yellow interval, when drivers approach a signalized intersection, they need either to proceed and cross the intersection or stop safely before the stop line. The objective of this study is to identify significant factors that impact driver's decision at yellow interval in dilemma zone. Data was collected using questionnaire survey and video recording technique at two signalized intersections in Duhok city for the period of peak and off-peak hours. Assessing the effects of influential factors including vehicle speed, distance to the stop line and vehicle type on driver behavior has been achieved through observations of trends from graphs and statistical analyses using Logistic regression. Results of questionnaire survey indicate that the younger drivers of (18-30) years are more aggressive and end up running a red light. Moreover, the results of trend analysis showed that number of drivers who run the yellow decreases as the distances to stop line increases and dilemma zone at peak hours are located nearer to the stop line as compared to off peak hours. The lower green time to cycle time ratio in four leg intersection increased the probability of crossing the intersection instead to wait for another green period. Results of all three parts show that both the vehicle speed and distance to the stop line are significant factors affecting driver decision.
\end{abstract}

KEYWORDS: Signalized Intersection; Driver Behavior; Yellow Interval; Dilemma Zone, Logistic Regression

\section{INTRODUCTION}

$\mathbf{T}$ raffic signals are operated at intersections to control traffic and pedestrian movements. Proper timing of color indications results in efficient operation of the signals and reduction in the probability of crashes. The yellow indication mainly serves to alert drivers that the signal indication is about to change from green to red (Garber and Hole, 2009). It also allows the vehicles that entered the intersection to safely clear the intersection before the conflicting movements receive the green indication (Roess et al, 2004). Due to different conflicting maneuvers and traffic interaction between road users (vehicle, roadway and driver) signalized intersections represent important part of the highway system to study driver behavior which is a major contributor to crashes at signalized intersections (Schattler and Datta, 2004). According to statistics, more than 50 percent of crashes occurs at yellow period at signalized intersections (Yang et al., 2014). At the start of yellow interval, vehicles approaching the intersection caught in a zone in which the driver has to come to a decision; either proceed 
and clear the intersection or stop safely before the stop line, which is defined as dilemma zone. The presence of dilemma zone is one of the main contributory factors to safety and efficiency of intersections and relates positively to crashes occurred at traffic signals. The dilemma zone concern has been studied in the literature by Gazis et al. (1960). There are two types of dilemma zone that introduced by many researchers; type I dilemma zone and type II dilemma zone (Parsonson, 1974, Urbanik and Koonce, 2007 and Li et al., 2013). Type I dilemma zone which was first considered by Gazis et al. (1960), where drivers neither stop safely nor clear the intersection before the red signal comes on. Type II dilemma zone is called option zone when officially identified by a technical committee of the southern section of ITE in 1974 (Parsonson, 1974). In option zone drivers are able to stop or cross safely at the start of yellow.

To reduce the effect of red-light running and help drivers to make a right decision at the indication of yellow, Yan et al. (2005), examined the effect of pavement marking on driver behavior at yellow interval. The results showed that there was $74.3 \%$ decrease in red light running when using pavement marking countermeasure. The brake deceleration rate without marking was larger than that with marking, in which a smaller deceleration indicates less probability that a rear crash happens. Yang et al. (2014) used fuzzy decision tree model and logistic regression to investigate driver behavior in yellow time at signalized intersections. The authors found that the stopping probability at intersection with countdown timer is smaller than that of the intersection without countdown and driver's decision is greatly depends on the distance to the stop line. Koll et al. (2004) indicated that the number of early stops increased at intersections with flashing green and the stopping process explained by speed and distance to stop line.
Felicio et al. (2015) examined driver behavior at signalized intersections using both survey study and actual driver behavior study through video recording technique of intersections with various types of traffic lights: lights having countdown timers, flashing lights and lights without warning. The surveys indicated that $76.3 \%$ of drivers stated they reduce speed at the commencement of yellow lights, $99.5 \%$ stop at red lights and 98.2\% accelerate at green lights. Results of actual driver behavior showed that startup time decreased at countdown timers and the percentage of cars that accelerate at yellow lights increased.

A study reported by Rakha et al. (2008) indicated that the distance from the stop bar at the onset of phase change, the gender of the driver and the age are influential factors to stopping/running behavior of driver at signalized intersections with high speed. Using driving simulator and questionnaire survey, Oda et al. (2007) found that the distance of the vehicle to stop line affected the driver's decision. Also, the results of questionnaire survey indicated that the driver's decision is influenced by the condition of pedestrian signal. Pathivada and Perumal (2017) investigated dilemma zone's effect on driver behavior at two signalized intersections on mixed traffic condition. Using binary logistic regression the results showed that distance from the stop line, vehicle speed, vehicle type and yellow light time have significant impact on drivers' decision. Using binary logistic regression and Artificial Neural Network analysis, Al-Jamman et al. (2018) found that drivers' decision in yellow time is affected by distance of the vehicle to the stop line. It was also found that the stopping probability increased by $26 \%$ at intersections with monitoring system. To evaluate drivers' decision at the onset of yellow time at signalized intersections, al-Kubaisi (2009) indicated that the major cause of conflicts for all intersections was the acceleration through yellow, stopping

${ }^{1}$ Corresponding author: College of Engineering, University of Duhok, Kurdistan Region, Iraq. 
suddenly and running red respectively. Talabany (2009) studied driver behavior in yellow interval at three signalized intersections in Arbil City/Iraq. The author found that aggressive behavior of drivers and high approaching speed cause a large percentage of drivers to caught in dilemma zone in the yellow interval. In addition, Wang et al. (2019) performed a study to explore the probability of rear-end crashes depending on driving tendency (stop/go) in dilemma zone at yellow onset. The results showed that the driver decision has a great effect on the probability of rear-end crashes. The aim of this study is to evaluate driver behavior in yellow interval at signalized intersections. The overall objective of current study is to identify significant factors that affect driver's decision (stop/go) at dilemma zone using questionnaire survey, general trends and statistical analysis by logistic regression.

\section{METHODOLOGY AND DATA COLLECTION}

To study driver behavior in yellow interval at signalized intersections survey questionnaire and field study were used. The two methods were compared to identify common opinions and preferences of drivers and how the actual behavior of drivers affect their decision.

\subsection{Survey Questionnaire}

A survey questionnaire was performed to identify the common opinions and behavior of drivers at the commencement of yellow period. The survey sheet consists of personal information of drivers including gender, age and education level. It also includes drivers' response with vehicle and intersection characteristics, traffic condition and signal setting. The last part of questionnaire relates to information on the factor that drivers believe influences on their decision in yellow interval. About 300 survey questionnaire forms were randomly distributed among drivers in different places (such as university campus, shopping malls and government authorities, etc.) to represent all drivers categories in Duhok city. A total of 250 complete and reliable forms were returned back and used in the analysis.

\subsection{Field Survey}

Data at two signalized intersections were collected using video recording technique. It was necessary to find a suitable point situated on a high place (such as a building) to cover a sufficient approach length (at least $100 \mathrm{~m}$ to the stop line) and to see the changes of traffic signal from this point. The selected intersections were Zariland (later will be indicated as (Z) intersection) of four legs and Baroshke (later will be indicated as (B) intersection) of three legs in Duhok city. The site plane of both intersections is given in Figure 1. Traffic volume data was collected for three normal days for each 15 minute interval to find the variation of flow and determine the peak and off-peak hours. The vehicles were classified into three classes; passenger cars (including taxis and minibuses), buses and trucks. At each approach (length of $100 \mathrm{~m})$ reference lines were marked with $10 \mathrm{~m}$ interval before starting the filming process to obtain accurate location of each approaching vehicle from the stop line. The base line of $30 \mathrm{~m}$ was used for speed measurement (Pathivada and Perumal, 2017). The speed was calculated depending on the base line length and the arrival and departure time of the selected vehicles for the chosen base line length. Response of drivers (stop or go) and probability of stopping at the start of yellow interval was collected from processing of the abstracted data from video recording technique. The probability of stopping was calculated by dividing the number of stopped vehicles over total number of vehicles for each distance from stop line. Signal timing data including total cycle length, green, yellow and red time were obtained from both signal indication recorded by video camera and onsite by stop watch. However, the geometric characteristics were obtained by site survey. Table 1 shows the details of each intersection characteristics. 

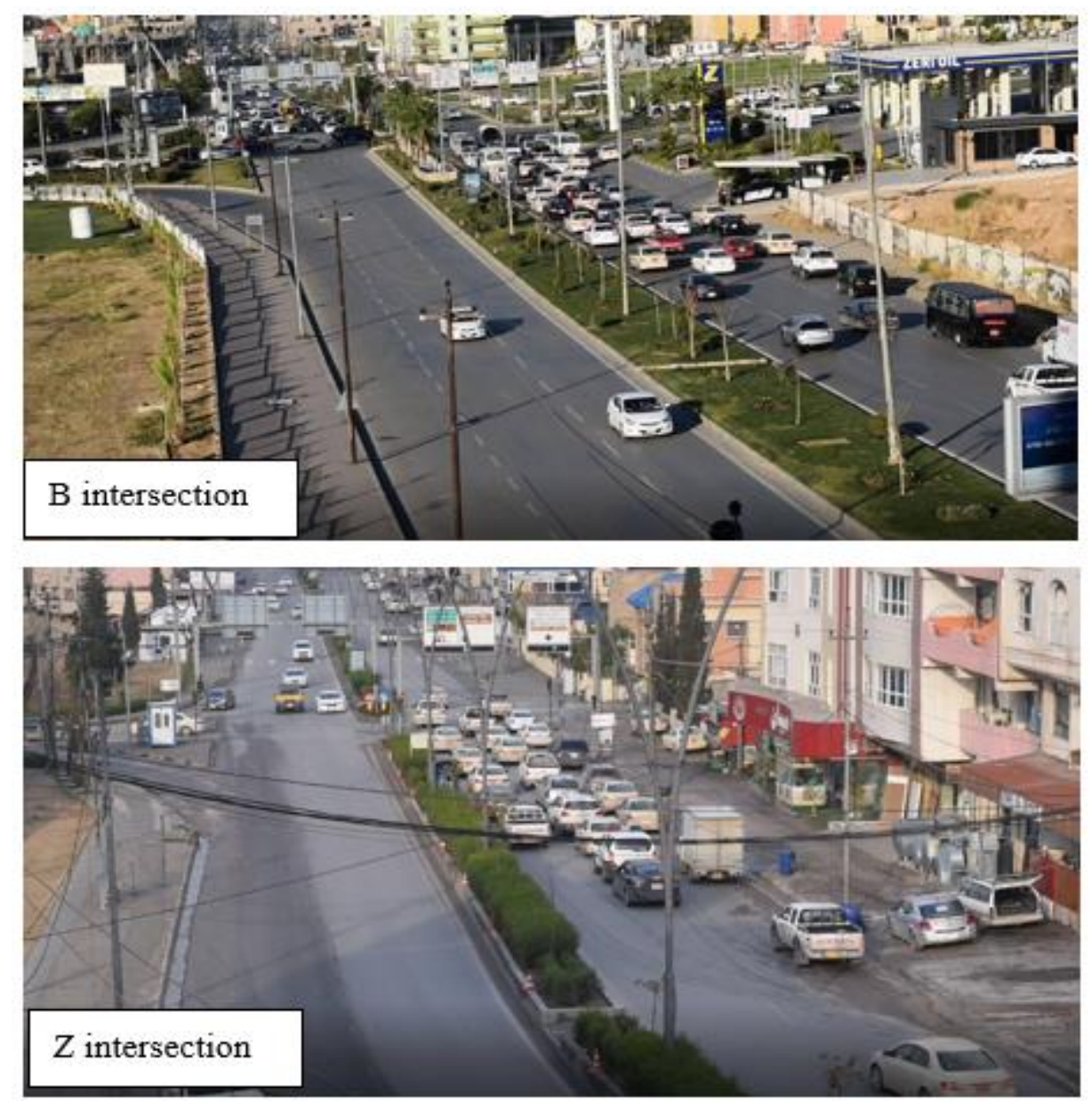

Fig. (1): The site plane of both $\mathrm{Z}$ and $\mathrm{B}$ intersections

\subsubsection{Data Abstraction and Processing}

The collected field data were abstracted by video player and personal computer. The abstraction process of the required data was carried out by playing back each video tape a number of times and with the aid of EVENT computer software developed by Al-Neami (1995). This software enabled more accurate time values to be obtained from the recordings.

Table (1): Intersection geometry and signalization timing data

\begin{tabular}{ccc}
\hline Location & Zari land intersection (Z) & Baroshke Intersection (B) \\
\hline Number of lanes & 3 & 3 \\
\hline Width of approach & $12 \mathrm{~m}$ & $9.15 \mathrm{~m}$ \\
\hline Number of arms(legs) & 4 & 3 \\
\hline Intersection depth & $35 \mathrm{~m}$ & $26.5 \mathrm{~m}$ \\
\hline Cycle length & $195 \mathrm{sec}$ & $103.5 \mathrm{sec}$ \\
\hline Green time & $45 \mathrm{sec}$ & $35 \mathrm{sec}$ \\
\hline Yellow time & $4 \mathrm{sec}$ & $3.5 \mathrm{sec}$ \\
\hline Red time & $146 \mathrm{sec}$ & $65 \mathrm{sec}$ \\
\hline
\end{tabular}

\footnotetext{
${ }^{1}$ Corresponding author: College of Engineering, University of Duhok, Kurdistan Region, Iraq.
} 


\subsubsection{Statistical Modeling by Logistic Regression}

To evaluate the effect of different factors on driver decision (stop/go), binary logistic model was used. As driver behavior in yellow interval is discrete in nature and driver encountering the yellow signal has two options to select (stop or go), binary logistic regression is an appropriate model for this analysis (Tranmer and Elliot, 2008). The dependent variable (driver behavior) is categorical (indicate 0 if cross the intersection and 1 if stop), therefore

$$
\log i t \pi=\ln \left(\frac{\pi i}{1-\pi i}\right)=\beta 0+\beta 1 X 1+\beta 2 X 2+\ldots+\beta J X J
$$

where

$\pi$ is the probability that a driver makes a stop decision at yellow time

$\mathrm{xj}$ is $\mathrm{jth}$ independent variable $\mathrm{j}=1,2, \ldots, \mathrm{J}$, such as vehicle speed, distance to the stop line and vehicle type and

$\beta$ is a regression coefficient.

\section{DATA ANALYSIS, RESULTS AND DISCUSSION}

This section focuses on the preliminary analysis of the collected data from questionnaire survey method including descriptive analysis for driver behavior by several variables such as gender, age group, education level, the reason for crossing the intersection, vehicle speed and distance to the stop line. It also includes general trends of different factors with driver stop/go decision. Furthermore, this section consists of statistical analysis of the collected data to determine how different factors affect drivers at yellow interval at signalized intersections.

\subsection{Survey Questionnaire Analysis}

Totally 250 drivers participated among which $35 \%$ were females. Due to the reason that the survey was mostly distributed at university it was estimated that the majority of responders are graduated persons. Results of questionnaire survey indicate that the younger drivers with age group of (18-30) years are more aggressive and attempt to catch the yellow light and result in running through the start of red light time. Although, some of drivers stated that the reason to clear the intersection at yellow time is that they don't want to wait. However, the survey results of the most important question in the survey that was the one asking about factors which affect drivers' decision at the onset of yellow light show that both vehicle speed and distance to the stop line are signification factor influencing driver decision.

\subsection{Driver Behavior-General Trends}

The distribution of drivers who proceed at yellow over different distances from the stop line for both $\mathrm{Z}$ and B-intersections during peak and off-peak hours is shown in Figure 2. For Z-intersection, results of peak hour data indicates that $72 \%$ of the drivers within the distance of $50 \mathrm{~m}$ or less from the stop line (those who are near the stop line) decided to cross the intersection, and this percentage decreases as they are far away from the stop line. However, for off-peak hour, $77 \%$ of drivers proceed the yellow between 40 to $80 \mathrm{~m}$ from the stop line. This could be due to the lower traffic volume and more available space for drivers to move freely and accelerate comfortably. Results of the B-intersection in peak hour indicates that $61.4 \%$ of drivers are likely to decide to go if they are located at a distance of $40 \mathrm{~m}$ or less from the stop line at the yellow light and the percentage decreases as they are far away from the stop line. Similarly a decreasing trend can be seen in off-peak hour in which $75.6 \%$ of the drivers within the distance of $50 \mathrm{~m}$ or less from the stop line tend to run the yellow. 

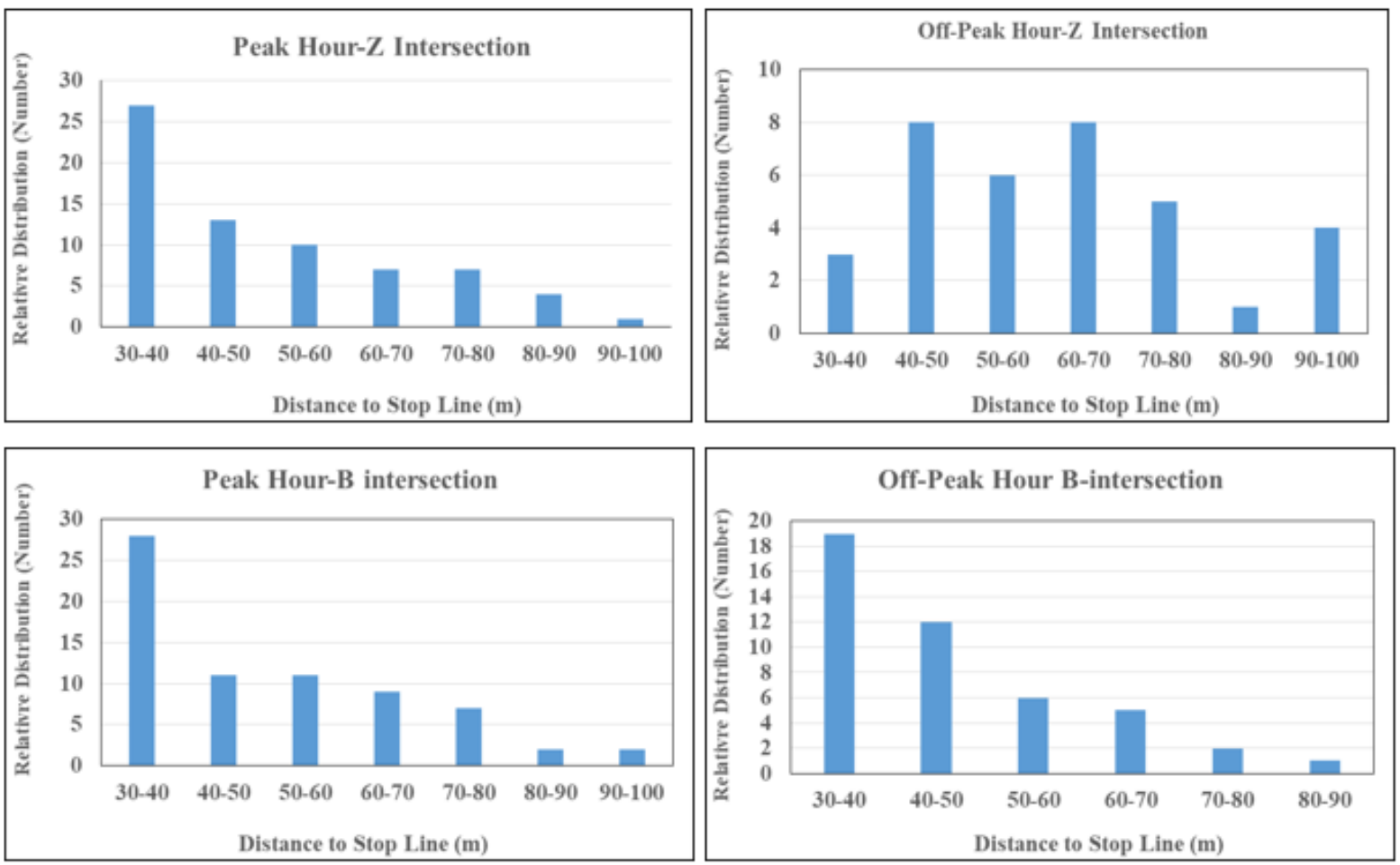

Fig. (2): Relative distribution (Number) of drivers who cross the intersection at yellow period

The cumulative percentiles of all crossing (yellow runner and red light runner) and stopping drivers against the distances to the stop line at the onset of yellow for $\mathrm{Z}$ and B-intersections for both peak and off-peak hours are given in Figure 3. Results of Z-intersection reveal that equivalent to the 10th and 90th percentiles of stops after the start of yellow, the dilemma zone from the stop line comes approximately between $24 \mathrm{~m}$ and $84 \mathrm{~m}$ for peak hour and between 49 and $95 \mathrm{~m}$ for off peak hour. It also indicates that the dilemma zone as the distance from the stop line between which $10 \%$ and $90 \%$ of drivers will chose to stop in reaction to yellow signal. Nearly $50 \%$ stopping/crossing decision point at peak hour occurred when the vehicles were at $52 \mathrm{~m}$ from the stop line. For off-peak hour the $40 \% / 60 \%$ stopping/crossing point occurred at $72 \mathrm{~m}$ from the stop line.
In addition, results of B-intersection reveal that equivalent to the 10th and 90th percentiles of stops after the start of yellow, the dilemma zone from the stop line comes approximately between $34 \mathrm{~m}$ and $88 \mathrm{~m}$ for peak hour and between 38 and $83 \mathrm{~m}$ for off peak hour. Nearly $40 \% / 60 \%$ stopping/crossing decision point at peak hour occurred when the vehicles were at 56 $\mathrm{m}$ from the stop line. For off-peak hour $35 \% / 65 \%$ stopping/crossing point occurred at $54 \mathrm{~m}$ from the stop line. It is obvious that the dilemma zone at peak hours are occurred closer to the stop line as compared to off peak hours. It is confirmed that the dilemma zones depend on the vehicle positions at the start of the amber phase. This is due to the reason that at off-peak hour drivers have more freedom to increase their speeds and cross the intersection from farthest distances.

${ }^{1}$ Corresponding author: College of Engineering, University of Duhok, Kurdistan Region, Iraq. 


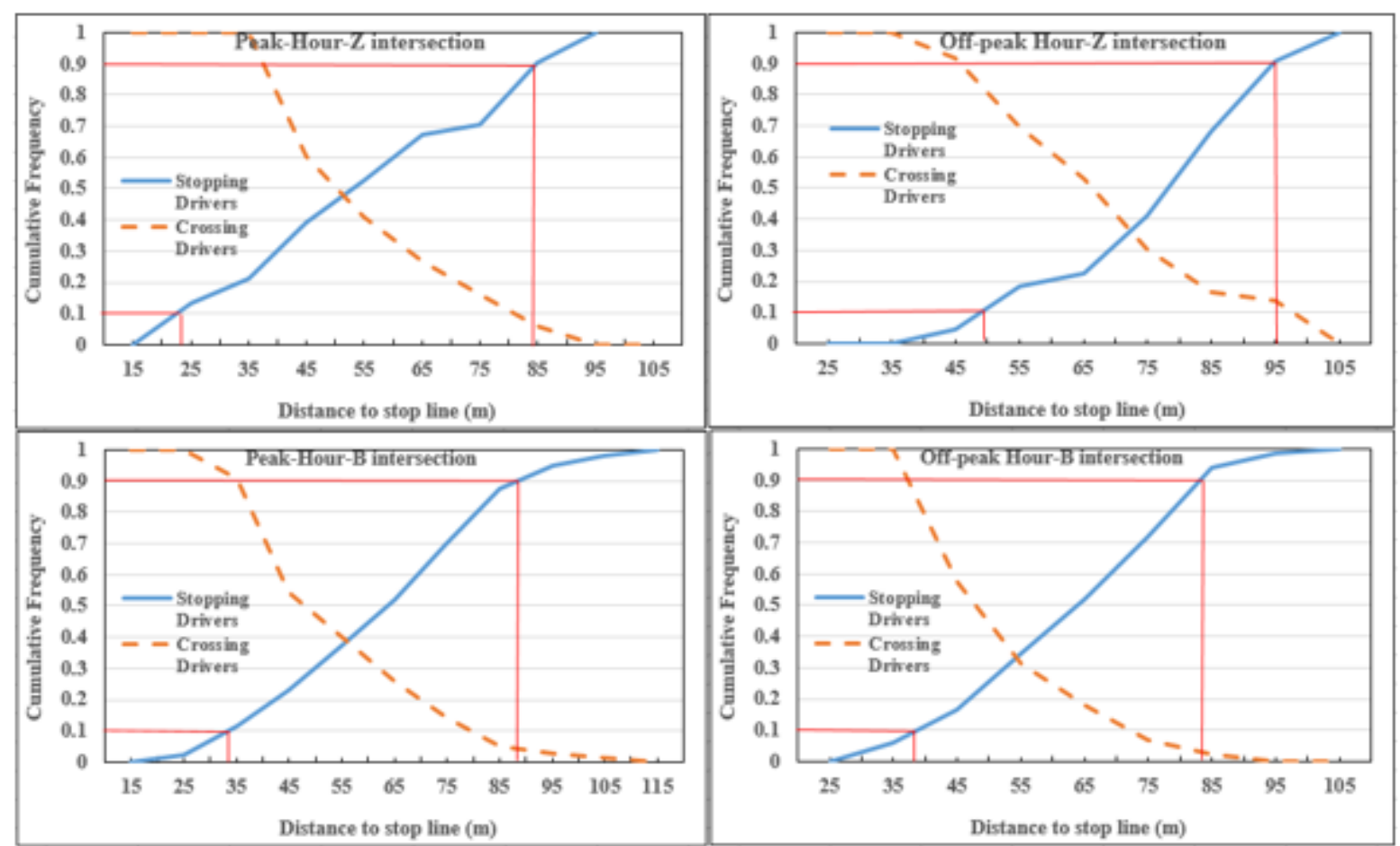

Fig. (3): Probability of stopping/crossing at yellow interval

The response of drivers at the start of yellow interval for $\mathrm{Z}$ and B-intersections is shown in Figure 4. This figure shows the relationship between distance to stop line and vehicle approach speed for two categories of drivers (run through the yellow period and stop at the start of yellow period). For Z-intersection, it can be seen that most of the drivers who proceed the yellow interval took $3 \mathrm{sec}$ or less to clear the intersection safely. However, most drivers who decided to stop at yellow were found at distances of $40 \mathrm{~m}$ and over from the stop line for peak hour and $50 \mathrm{~m}$ and over for off-peak hour.

Similarly, for B-intersection, most of the drivers who proceed the yellow time took $3 \mathrm{sec}$ or less to cross the intersection safely and drivers who decided to stop at yellow time were observed at distances of $30 \mathrm{~m}$ and over from the stop line for peak hour and $40 \mathrm{~m}$ and over for off-peak hour. Comparing the results of both intersections it can be found that as the $\mathrm{Z}$ intersection has greater intersection clearance distance (a distance covered by an approaching vehicle to reach to the opposite approach) and wider approach, it is clear that drivers are expected to cross during the red at peak hour (Bonneson et al., 2001). This lead to the condition that the drivers decided to stop at farthest distances from the stop line.

Distribution of driver behavior at the onset of yellow is given in Table 2. It gives an over view of the driver behavior decision at the onset of yellow. The go responses (includes both the drivers crossing the intersection at yellow period and drivers end up running the red) at Z-intersection at the farther distances from stop line are related to red runners that make $18 \%$ of the observations at peak hour and $6 \%$ at off-peak hour. Also it is related to the lower green time to cycle time ratio of 0.23 for $\mathrm{Z}$-intersection instead to wait for another green indication as compared to the ratio of 0.34 for B- intersection (refer to Table 1). This results are consistence with previous studies (Abbas et al., 2014). Although the percentage of drivers who run the yellow for B-intersection is lower as compared to Z-intersection, however, it includes a large percent (17\%) of red runner. This could be 
related to shortest cycle time as compared to B-intersection. Also this may be due to the fact that drivers become more confused with delay at signalized intersections. The results are consistent with previous researchers (Brewer et al., 2002). In general, the results indicate that nearly half of drivers are running the yellow and trying to obey the traffic restrictions.
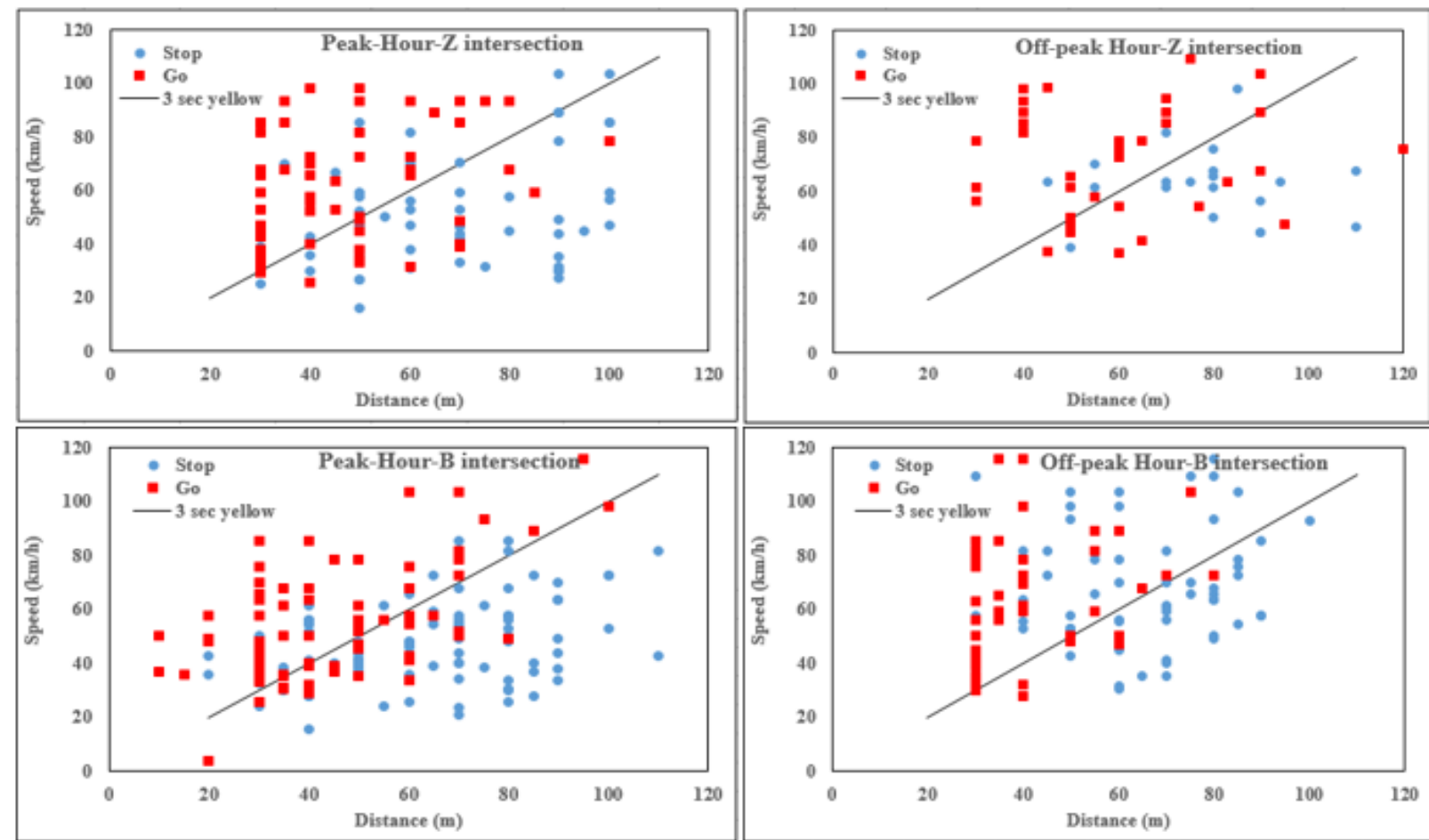

Fig. (4): Driver behavior at the onset of yellow

Table (2):. Distribution of driver behavior at the onset of yellow

\begin{tabular}{lcccccc}
\hline & \multicolumn{3}{c}{ Z-intersection } & \multicolumn{3}{c}{ B-intersection } \\
\hline & Stop (\%) & Go (\%) & Red Runner (\%) & Stop (\%) & Go (\%) & Red Runner (\%) \\
\hline Peak & 47 & 53 & 18 & 55 & 45 & 17 \\
\hline Off-peak & 38 & 62 & 6 & 60 & 40 & 17 \\
\hline
\end{tabular}

The relationship between vehicle's distance to stop line and probability distribution of stopping for both intersections at peak and off-peak hours is given in Figure 5. It can be seen that for Z-intersection, the stop probability for peak hour increases between distances from the stop line of 30 to $100 \mathrm{~m}$. However, the stop probability increases between distances from the stop line of 30 to $110 \mathrm{~m}$ for off-peak hour. The results for B-intersection indicates that probability of stopping as a function of distance to stop line increases between distances from the stop line of 20 to $100 \mathrm{~m}$ for peak hour. However, the stop probability increases between distances from the stop line of 30 to $100 \mathrm{~m}$ for off-peak hour. It also can be found that the stop probability curve for peak hour is shifted to the left when compared to stop probability curve for off-peak hour and it is more evidence at B-intersection. This is due to that the stopping probability increases at short yellow phase.

${ }^{1}$ Corresponding author: College of Engineering, University of Duhok, Kurdistan Region, Iraq. 


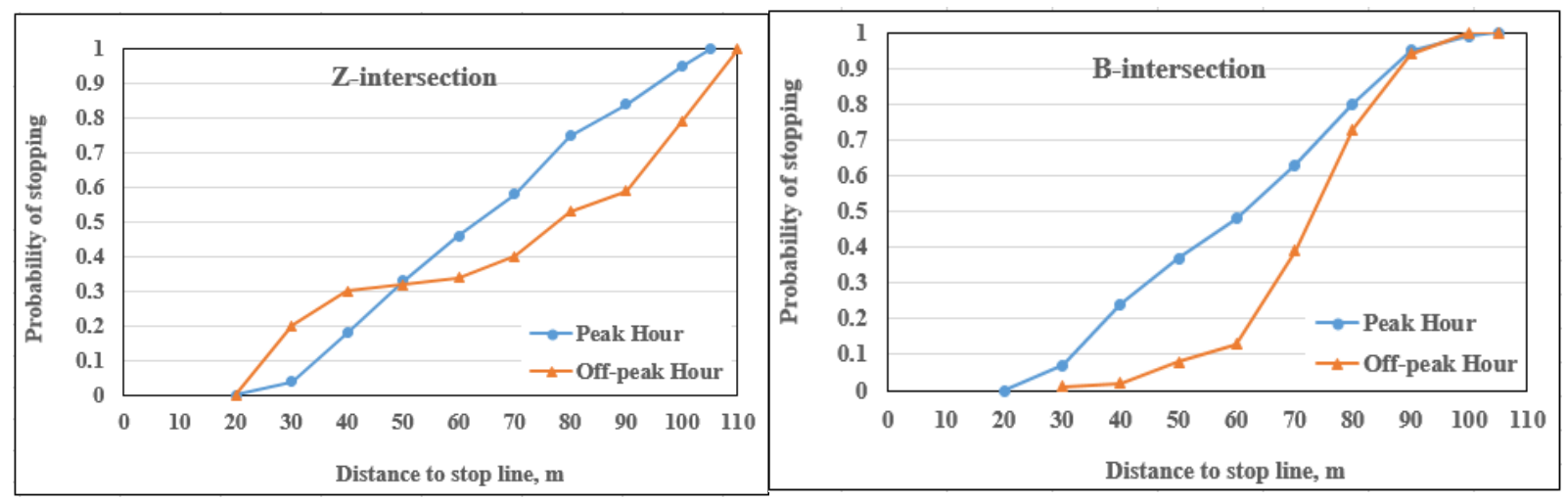

Fig. (5):. Probability of stopping as a function of distance to stop line.

The relationship between vehicle approach speed and probability of stopping for both intersections at peak and off-peak hours is shown in Figure 6. For Z-intersection the probability of stopping increases for approach speed between 10 to $100 \mathrm{~km} / \mathrm{h}$ at peak hour and at off-peak hour it starts to increase from 30-110 $\mathrm{km} / \mathrm{h}$. However, for B-intersection the probability of stopping increases for approach speed between 20 to $100 \mathrm{~km} / \mathrm{h}$ at peak hour and at off-peak hour it starts to increase from 40-110 $\mathrm{km} / \mathrm{h}$. Similarly, the stop probability curve for peak hour is shifted to the left when compared to stop probability curve for off-peak hour and it is more evidence at B-intersection. The difference in stop probability between both intersections (the $\mathrm{Z}$ intersection has greater intersection clearance distance and wider approach) is related to their geometric characteristics and signal timing ( $\mathrm{Z}$ intersection has longer cycle time). Also the results reveal that both distance to stop line and approach speed are two important factor affecting driver decision.
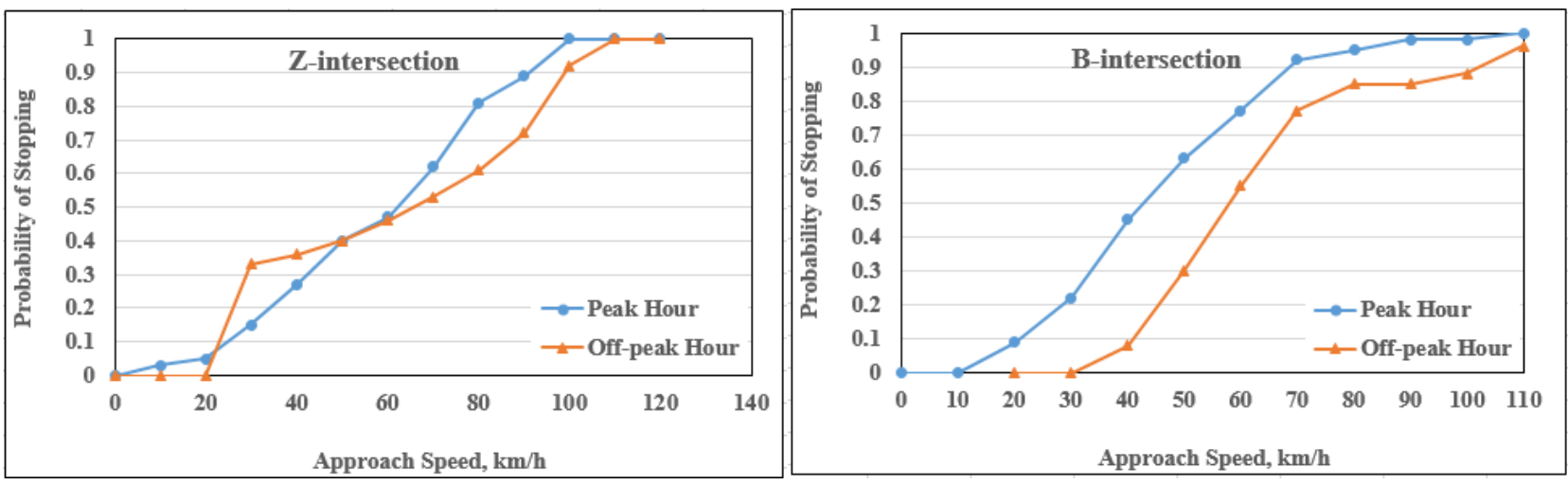

Fig. (6): Probability of stopping as a function of approach speed

\subsection{Modeling of the Driver Behavior}

As mentioned in the previous section, driver behavior model (stop/go decision) at signalized intersections (approach level analysis) was fitted by applying binary logistic regression using
SPSS version 23. Independent variables including distance of approaching vehicle to stop line, vehicle approach speed at the onset of yellow and the vehicle type with two categories $(\mathrm{PCU}=1$, Others (Bus and Truck) $=2$ ) have been 
explored for their effects on the dependent variable which is driver's decision in yellow time at signalized intersections represented by $1=$ the choice to stop, and $0=$ the choice to accelerate and cross the intersection. The model was developed for both intersections and during peak and off-peak hours.

\subsubsection{Results of binary logistic model at Z-Intersection during Peak and Off-Peak Hours}

The results of binary logistic model to expect the probability of stopping at Z-intersection during peak and off-peak hours based on these variables are given in Table 3. It is important to highlight that the model in the below table includes both significant and non-significant independent variables. Table 3 shows regression coefficients $(\beta)$, standard error and odds ratios for the independent variables $(\exp (\beta))$. An index of significance of each independent variable in the regression model is presented by $\mathrm{p}$-value at the $95 \%$ confidence level. An odds ratio can be interpreted as the multiplicative change in the probability of stopping per unit change in the independent variable (Hosmer and Lemeshow, 2013). The percent change in the probability of stopping with a unit change in the explanatory variables is estimated by subtracting 1 from the odds ratio and multiplying by 100 (Hosmer and Lemeshow, 1989).

Table (3): Estimated binary logistic model for Z-intersection

\begin{tabular}{|c|c|c|c|c|c|c|c|c|}
\hline \multirow[b]{2}{*}{ Parameter } & \multicolumn{4}{|c|}{ Peak Hour } & \multicolumn{4}{|c|}{ Off-Peak Hour } \\
\hline & $\begin{array}{l}\text { Coefficient } \\
\qquad s(\beta)\end{array}$ & Std. Error & P-Value & $\begin{array}{l}\text { Exp } \\
(\beta)\end{array}$ & $\begin{array}{l}\text { Coefficients } \\
(\beta)\end{array}$ & Std. Error & P-Value & $\operatorname{Exp}(\beta)$ \\
\hline Intercept & -0.392 & 0.971 & 0.686 & 0.676 & 0.198 & 1.973 & 0.920 & 1.219 \\
\hline $\begin{array}{l}\text { Distance to } \\
\text { intersection }\end{array}$ & 0.052 & 0.011 & 0.000 & 1.054 & 0.048 & 0.017 & 0.005 & 1.050 \\
\hline $\begin{array}{c}\text { Vehicle approach } \\
\text { speed }\end{array}$ & -0.031 & 0.010 & 0.002 & 0.970 & -0.033 & 0.018 & 0.074 & 0.968 \\
\hline $\begin{array}{c}\text { Type of } \\
\text { vehicle }(1)^{*}\end{array}$ & -0.928 & 0.797 & 0.244 & 0.395 & -1.988 & 1.182 & 0.093 & 0.137 \\
\hline $\begin{array}{c}\text { Number of } \\
\text { observations }\end{array}$ & 131 & & & & 58 & & & \\
\hline
\end{tabular}

*Reference case for category variable $=2$

Results of peak hour data illustrate that not all predictors are significant in driver behavior. Among them, the vehicle type is not significant as $(\mathrm{P}>0.05)$. The intercept is the expected probability of stopping when all variables in the model are evaluated at zero. That is:

The expected probability of stopping is exp $(-0.392) /(1+\exp (-0.392))=0.4$.

The positive sign of the distance to stop line variable shows that the probability of stopping increases with the increase in distance of vehicles to the stop line at the onset of yellow. Using the odds ratios provided in Table 3, for each $1 \mathrm{~m}$ increase in distance to stop line, the probability of stopping increases by $5.4 \%$ (odd ratio=1.054). As larger travel time to the intersection at start of yellow is more likely to results in a stopping event. The negative sign for the variable speed, indicates that with an increase in speed of vehicles approaching the intersection the probability of stopping decreases. Using the odds ratios, for each $1 \mathrm{~km} / \mathrm{h}$ increase

${ }^{1}$ Corresponding author: College of Engineering, University of Duhok, Kurdistan Region, Iraq. 
in speed, the probability of stopping decreases by $3 \%$ (odd ratio $=0.97$ ). These results are supporting the findings of previous researches (Lum and Wong, 2001 and Yang et al. 2014). Stopping probability appeared that was not affected by the vehicle type. This may be attributed to lower number of buses and trucks in the observations. The result is consistent with Al-Jamman et al. (2018).

Results of off-peak hour data illustrate that the intercept is the expected probability of stopping when all variables in the model are evaluated at zero. That is:

The expected probability of stopping is exp $(0.198) /(1+\exp (0.198))=1$.

The positive sign of the distance to stop line variable illustrates that the probability of stopping increases with the increase in distance to the stop line at the onset of yellow. Using the odds ratios provided in Table 3, for each $1 \mathrm{~m}$ increase in the distance to stop line, the probability of stopping increases by $5.0 \%$ (odd ratio=1.050).

\subsubsection{Results of binary logistic model at B-Intersection during Peak and Off-Peak Hours}

The results of binary logistic regression model to expect the probability of stopping at B-intersection during peak and off-peak hours based on the predictors are given in Table 4 . Results illustrate that not all predictors are significant in driver behavior. Among them, the vehicle type is not significant as $(P>0.05)$. The intercept is the expected probability of stopping when all variables in the model are evaluated at zero. That is:
The expected probability of stopping is exp $(-0.646) /(1+\exp (-0.646))=0.34$.

The positive sign of the distance to stop line variable explains that the increase in distance to the stop line results in an increase in the probability of stopping at the onset of yellow. Using the odds ratios provided in Table 4, for each $1 \mathrm{~m}$ increase in distance to stop line, the probability of stopping increases by $7.6 \%$ (odd ratio=1.076). The negative sign for the variable speed, indicates that that with an increase in speed of vehicles approaching the intersection the probability of stopping decreases. Using the odds ratios, for each $1 \mathrm{~km} / \mathrm{h}$ increase in speed, the probability of stopping decreases by $5.9 \%$ (odd ratio=0.941). Results of off-peak hour data illustrate that the intercept is the expected probability of stopping when all variables in the model are evaluated at zero. That is:

The expected probability of stopping is exp $(-2.518) /(1+\exp (-2.518))=0.074$.

The positive sign of the distance to stop line variable indicates that an increase in distance to the stop line results in an increase in the probability of stopping at the onset of yellow. Using the odds ratios provided in Table 4, for each $1 \mathrm{~m}$ increase in the distance to stop line, the probability of stopping increases by $9.2 \%$ (odd ratio=1.092). Also, the results indicated that the vehicle approach speed is not a significant factor exploring driver behavior during the off-peak hours. This could be due to the fact that during off-peak hour all drivers are driving freely and there is no restriction to their movements. Therefor this variable didn't show any variation in the driver decision. 
Journal of University of Duhok, Vol. 23, No.2 (Pure and Eng. Sciences), Pp 142-156, 2020 (Special Issue)

$3^{\text {rd }}$ international conference on recent innovations in engineering (ICRIE) Duhok, September 9-10-2020

Table (4): Estimated binary logistic model for B-intersection

\begin{tabular}{|c|c|c|c|c|c|c|c|c|}
\hline \multirow[b]{2}{*}{ Parameter } & \multicolumn{4}{|c|}{ Peak Hour } & \multicolumn{4}{|c|}{ Off-Peak Hour } \\
\hline & $\begin{array}{l}\text { Coeffici } \\
\text { ents }(\beta)\end{array}$ & $\begin{array}{l}\text { Std. } \\
\text { Erro } \\
r\end{array}$ & $\begin{array}{c}\text { P-Val } \\
\text { ue }\end{array}$ & $\begin{array}{l}\text { Exp } \\
(\beta)\end{array}$ & $\begin{array}{l}\text { Coeffici } \\
\text { ents }(\beta)\end{array}$ & $\begin{array}{l}\text { St } \\
\text { d. } \\
\text { Err } \\
\text { or }\end{array}$ & $\begin{array}{c}\text { P-Val } \\
\text { ue }\end{array}$ & $\begin{array}{l}\text { Exp } \\
(\beta)\end{array}$ \\
\hline Intercept & -0.646 & $\begin{array}{c}0.76 \\
5\end{array}$ & 0.399 & 0.524 & -2.518 & $\begin{array}{l}1.0 \\
93\end{array}$ & 0.021 & 0.081 \\
\hline $\begin{array}{l}\text { Distance to } \\
\text { intersection }\end{array}$ & 0.074 & $\begin{array}{c}0.01 \\
2\end{array}$ & 0.000 & 1.076 & 0.088 & $\begin{array}{l}0.0 \\
17\end{array}$ & 0.000 & 1.092 \\
\hline $\begin{array}{c}\text { Vehicle approach } \\
\text { speed }\end{array}$ & -0.061 & $\begin{array}{c}0.01 \\
3\end{array}$ & 0.000 & 0.941 & -0.009 & $\begin{array}{l}0.0 \\
09\end{array}$ & 0.290 & 0.991 \\
\hline Type of vehicle $(1)^{*}$ & 0.114 & $\begin{array}{c}0.56 \\
9\end{array}$ & 0.842 & 1.120 & -0.934 & $\begin{array}{l}0.6 \\
23\end{array}$ & 0.134 & 0.393 \\
\hline $\begin{array}{l}\text { Number of } \\
\text { observations }\end{array}$ & 173 & & & & 112 & & & \\
\hline
\end{tabular}

*Reference case for category variable $=2$

Depending on the results of binary logistic the regression equation with significant model for both $\mathrm{B}$ and $\mathrm{Z}$ intersections during both predictors are given in Table 5. peak and off-peak hours shown in Tables 3 and 4,

Table (5): Binary logistic model equation

\begin{tabular}{cc}
\hline & Regression Equation \\
\hline $\begin{array}{cc}\text { Z-Intersection-Peak } \\
\text { Hour }\end{array}$ & $\begin{array}{c}P(\text { stopping })=e^{\wedge}(-0.392+0.052 * \text { Distance }-0.031 * \text { Speed }) / 1 \\
\\
\end{array}$ \\
$\begin{array}{cc}\text { Z-Intersection-Off } \\
\text { peak Hour }\end{array}$ & $\begin{array}{c}e^{\wedge}(-0.392+0.052 * \text { Distance }-0.031 \\
\text { B-Intersection-Peak })\end{array}$ \\
Hour & $P($ stopping $)=e^{\wedge}(0.198+0.048 *$ Distance $) / 1+e^{\wedge}(0.198+0.048$ \\
& $+e^{\wedge}(-0.646+0.074 *$ Distance $)$ \\
\hline B-Intersection-Off & $P($ stopping $)=e^{\wedge}(-2.518+0.088 *$ Distance $) / 1+e^{\wedge}(-2.518$ \\
peak Hour & $+0.088 *$ Distance $)$ \\
\hline
\end{tabular}

\subsection{Model Evaluation}

The goodness of fit test of the model was examined through the Hosmer-Lemeshow (H-L) statistic as given in Table 6. The H-L statistic is a Pearson Chi-square which is computed after categorizing the data into 10 equally sized groups based on the model predicted probabilities. The Pearson Chi-square is then used to test whether the observed proportions of stopped drivers are similar to the expected probabilities of drivers stopped in the groups formed above. A non- significant chi-square shows that the model fits well (Hosmer and Lemeshow, 2013). The H-L test results indicated

${ }^{1}$ Corresponding author: College of Engineering, University of Duhok, Kurdistan Region, Iraq. 
a Chi-square of 5.919 which was insignificant with $\mathrm{p}$-value $=0.656$ for $\mathrm{Z}$-intersection at peak hour and a Chi-square of 3.525 with $\mathrm{p}$-value $=$ 0.897 for Z-intersection at off-peak hour. In addition, The H-L test results indicated a Chi-square of 8.193 which was insignificant with $\mathrm{p}$-value $=0.415$ for B-intersection at peak hour and a Chi-square of 4.961 with $\mathrm{p}$-value $=$ 0.762 for B-intersection at off-peak hour. These test results accept the null hypothesis that the models suitable the data.

Table (6): Hosmer and Lemeshow Test Results

\begin{tabular}{ccc}
\hline & Chi-square & Significance. $^{*}$ \\
\hline $\begin{array}{c}\text { Z-intersection-Peak } \\
\text { hour }\end{array}$ & 5.919 & 0.656 \\
\hline $\begin{array}{c}\text { Z-intersection-Off-Peak } \\
\text { hour }\end{array}$ & 3.525 & 0.897 \\
\hline $\begin{array}{c}\text { B-intersection-Peak } \\
\text { hour }\end{array}$ & 8.193 & 0.415 \\
\hline $\begin{array}{c}\text { B-intersection-Off-Peak } \\
\text { hour }\end{array}$ & 4.961 & 0.762 \\
\hline
\end{tabular}

*Lower (non-significant) values indicate a smaller difference between the

predicted and the observed group membership and, therefore, good overall model fit.

\section{CONCLUSION AND RECOMMENDATIONS}

Factors affecting on the driver behavior in yellow interval at signalized intersections were analyzed based on questionnaire survey and collected data of the field study for two signalized intersections during peak and off-peak hours. The findings of questionnaire survey indicated that the younger drivers with age group of (18-30) years attempt to catch the yellow light and result in running a red light. Although, some of drivers stated that the reason to clear the intersection at yellow time is that they don't want to wait. However, the survey results of the most important question in the survey that was the one asking about factors which affect drivers' decision at the onset of yellow light show that both vehicle speed and distance to the stop line are signification factor influencing driver decision. Based on general trends, for both intersections and during both peak and off-peak hours it has been found that most of the drivers who are near the stop line decided to pass over, and this percentage decreases as they are more far away from the stop line. It is also found that the dilemma zone at peak hours are located closer to the stop line as compared to off peak hours. The lower green time to cycle time ratio in Z-intersection increased the probability of going instead to wait for another green indication as compared to B-intersection. The probability of stopping as a function of distance to stop line and vehicle approach speed for both intersections indicates that the stop probability curve for peak hour is shifted to the left when compared to stop probability curve for off-peak hour and it is more evidence at B-intersection. This is due to that the stopping probability increases at short yellow phase. The difference in stop probability between both intersections is related to their geometric characteristics and signal timing. The results of trend analysis also reveal that both distance to stop line and approach speed are two important factor affecting driver decision.

Analysis of driver's decision (stop/go) by logistic regression indicates an increase in the probability of stopping as the distance to the stop line increases for both $\mathrm{Z}$ and $\mathrm{B}$ intersections at peak and off-peak hours at the onset of yellow and the probability of stopping decreases with increase in speed of vehicles approaching the intersection at peak hour. This is due to the reason that larger travel time to the intersection at start of yellow is more likely to results in a stopping event. The vehicle approach speed is not a significant factor exploring driver behavior during the off-peak hours due to lower traffic volume and therefore no restriction to drivers' movements. Stopping probability appeared that 
not affected by the vehicle type. This may be attributed to lower number of buses and trucks in the observations. The Hosmer-Lemeshow (H-L) test results for both intersections at peak and off-peak hours has confirmed that the models fit the data well.

Based on the results found it is recommended to use flashing green light of 3 seconds before yellow indication or count down green light to alert drivers that the green indication is about to finish. This could help in reducing dilemma zone and therefore red light runners. It is recommended to use red-light running enforcement cameras with indicated penalty for drivers who run the red light will also be useful in improving safety. It is recommended that consideration be given to increase the yellow interval duration and similar data collection and analysis be conducted to evaluate the effectiveness of lengthening the yellow interval. Because of the limitations, it is advisable to take more factors into consideration with more field data collection efforts in the future research.

\section{Acknowledgements}

The author acknowledges the support from Duhok Traffic Agency staff in Duhok city.

\section{References}

Abbas, M., Machiani, S., Garvey, P. M., Farkas, A. \& Lord-Attivor, R. (2014). Modeling the Dynamics of Driver's Dilemma Zone Perception Using Machine Learning Methods for Safer Intersection Control. MAUTC Report.

Al Jaman, S., Alam, M., \& Hamdi, A. (2018). Effects of automated traffic enforcement on driver behavior at a signalized intersection in Saudi Arabia. International Journal of Civil Engineering and Technology (IJCIET), Volume 9, Issue 2, pp. 389-401, Article ID: IJCIET_09_02_037.

AL-Kubaisi, M. L. (2009). The Dilemma at Signalized Intersection Dilemma Zone. Iraqi Journal of Civil Engineering. Vol.6 No.1.
Al-Neami, A. H. K. 1995. A Computer Program for Traffic Abstraction and Analysis.

Bonneson, J. A., Brewer, M. A. \& Zimmerman K.H. (2001). Review and evaluation of factors that affect the frequency of red-light-running. Transportation Research Board, 4027:78.

Brewer, M., Bonneson, J. \& Zimmerman, K. (2000). Engineering countermeasures to red-light-running. The ITE 2002 Spring Conference and Exhibit. Institute of Transportation Engineers; Washington, DC, USA: 2002.

Duhok Traffic Agency. (2019). Duhok.

Felicio, G. P., Grepo, L. C., Reyes, V. F. \& Yupingkun, L. C. (2015). Traffic light displays and driver behaviors: A case study. 6th International Conference on Applied Human Factors and Ergonomics (AHFE 2015) and the Affiliated Conferences, AHFE 2015.

Garber, N. J. \& Hoel, L. A. (2009). Traffic and Highway Engineering. (4th ed). USA.

Gazis, R., Herman, R. \& Maradudin, A. (1960). The problem of the amber signal light in traffic flow. Operations Research, 8, 112-130.

Hosmer, D. W. \& Lemeshow, S. (2013). Applied logistic regression. In: (3rd ed.). New York: Hoboken: Wiley.

Kennedy, J. \& Sexton, B. (2009). Literature review of road safety at traffic signals and signalized crossings. Transport Research Laboratory.

Koll, H., Bader, M. \& Axhausen, K. W. (2004). Driver behavior during flashing green before amber: a comparative study. Accident Analysis and Prevention. 36, 273-280.

Li, M., Zhang, L. \& Yang, X. (2013). A review of yellow dilemma problem and a dynamic speed guidance system design based on CVIS. 13th COTA International Conference of Transportation Professionals. Shenzhen.

Lum, K.M. \& Wong, Y. D. (2001). A before-and-after study of driver stopping propensity at red light camera intersections. Accident Analysis and Prevention. $\quad 35, \quad 111-120$, DOI: 10.1016/S0001-4575(01)00096-3.

${ }^{1}$ Corresponding author: College of Engineering, University of Duhok, Kurdistan Region, Iraq. 
Machiani, S.G. (2014). Modeling Driver Behavior at Signalized Intersections: Decision Dynamics, Human Learning, and Safety Measures of Real-time Control Systems. PhD thesis.

Oda, T., Suda, Y., Tanaka, S. \& Yamaguchi, D. (2007). Evaluation of stopping behavior of drivers in dilemma zone using driving simulation, Int. J. ITS Res., vol. 5, no. 1, pp. 47-54, 2007.

Parasonson, P. S., Roseveare, R. W. \& Thomas, J. M., JR. (1974). Small-area detection at intersection approaches. Traffic Engineering, 2 .

Pathivada, B.K. \& Perumal, V. (2017). Modeling driver behavior in dilemma zone under mixed traffic conditions. Transportation research procedia, 27, 961-968.

Rakha, H., El-Shawarby, I. \& Setti, José R. (2008). Characterizing Driver Behavior on Signalized Intersection Approaches at the Onset of a Yellow-Phase Trigger. Intelligent Transportation Systems, IEEE Transactions on. 8. 630 - 640. 10.1109/TITS.2007.908146.

Roess, R.P., Prassas, E.S. \& McShane W.R. (2004). Traffic Engineering. (3rd ed). Prentice Hall. NJ.

Schattler, K.L. \& Datta, K.T. (2004). Driver Behavior Characteristics at Urban Signalized Intersections. Transportation research record.
SPSS. (2016). Statistical Package for the Social Sciences for Windows, Version 23.

Talabany, A. F. S. (2009). Driver Behavior during Amber at Signalized Intersections in Arbil City. Zanco Journal of Pure and Applied Sciences.

Tranmer, M \& Elliot, M. (2008). Binary logistic regression. Cathie Marsh for Census and Survey Research.

Urbanik, T. \& Koonce, P. (2007) . The dilemma with dilemma zones. ITE District 6th Annual Meeting, Portland.

Wang, W., Li, Y., Lu, J., Li, Y. \& Wan, Q. (2019). Estimating rear-end accident probabilities with different driving tendencies at signalized intersections in China. Journal of Advanced Transportation, vol. 2019, Article ID 4836908, 11 pages, 2019.

Yan, X., Radwan, E., Klee, H. \& Guo D. (2005). Driver behavior during yellow change interval. Driving Simulation Conference, 88-97, Orlando, FL

Yang, Z. T. X., Wang W., Zhou X. \& Hongmei, L.H. (2014). Research on driver behavior in yellow interval at signalized intersections, Hindawi Publishing Corporation. Math Probl Eng 2014, 518782, DOI: 10.1155/2014/518782. United States of America Cengage Learning. 